\title{
Preservando a performatividade de performances e respeitando sua efemeridade
}

\section{Preserving the performativity of performance art while respecting ephemerality}

\author{
Helen Westgeest ${ }^{1}$ \\ Rachel Augusto ${ }^{2}$
}

DOI I0.265 I2/museologia.v9il8.34544

\begin{abstract}
Resumo
Esta pesquisa explora os conflitos que surgem ao serem aplicadas práticas documentais a arte performática. Embora a efemeridade das ações seja percebida como essencial para esse gênero artístico, profissionais e artistas, frequentemente, não são favoráveis ao desaparecimento de todos os aspectos dessas obras de arte. Os estudos de caso neste artigo demonstram que a efemeridade da obra de arte da performance original torna-se ainda mais considerada quando a performatividade da ação é preservada por meio de formas específicas de documentações fragmentadas. Proporcionando com isso, a sobrevivência e continualidade do caráter ativador, do encorporamento da experiência evocada, dos significados contingentes e das contínuas reinterpretações, como por meio de reencenações, de uma obra de arte performática.
\end{abstract}

\section{Palavras-chave}

Performance artística. Documentação. Efemeridade. Performatividade. Reencenação.

\begin{abstract}
This research explores the conflicts that emerge when applying recording and registration practices to performance art. Although the ephemerality of the actions is perceived as essential for this art genre, museum professionals and artists are often not in favor of disappearance of all aspects of these artworks. The case studies in this article demonstrate that the ephemerality of the original performance artwork becomes even more considered when the performativity of the action is preserved through specific forms of fragmented documentation. This enables the survival and continuation of a performance artwork's activating character, the embodied experience evoked, the work's contingent meanings, and its continuous reinterpretations, such as through re-enactments.
\end{abstract}

\section{Keywords}

Performance art. Documentation. Ephemerality. Performativity. Re-enactment.

In the twentieth century, and most prominently in the 1960s, some artists started to explore new forms of creating artworks in non-material-based formats. Consequently, museum professionals had to reconsider how to include these new artworks in their institutions. The common practice of conserving tangible items based on approved preservation procedures had to be drastically adapted. Aside from conservation, the documentation procedure is a fundamental practice in the field of Museology. Both activities, however, start from and mainly highlight the material features of artworks, an approach that in fact conflicts with the essence of intangible artworks.

I Associate Professor of Modern and Contemporary Art History at Leiden University, the Netherlands. PhD in Art History; webpage: www.universiteitleiden.nl/en/staffmembers/helen-westgeest; email: h.f.westgeest@hum.leidenuniv.nl. ORCID: https://orcid.org/0000-000I-9882-6I82.

2 Bachelor in Museology at the University of Brasilia. Master of Arts in Arts and Culture, with specialization in Museums and Collections at Leiden University. The main part of this article is based on Rachel Augusto's unpublished MA thesis "Creating Afterlives: Preserving Traces of Performance Art from a Museological Perspective”, supervised by Helen Westgeest in 2020. Email: rachelaugusto94@gmail.com. ORCID: https://orcid.org/0000-0002-4075-6828. 
Preservando a performatividade de performances e respeitando sua efemeridade

According to the International Council of Museums (ICOM), conservation refers to "all measures and actions aimed at safeguarding tangible cultural heritage while ensuring its accessibility to present and future generations" (Ibidem-CC, [2008]). In line with this goal, museum documentation relates to the elaboration, consolidation, and management of data and information about objects within museum collections (Ibidem-Cidoc, [20I2]). Regardless of the medium, once an artwork enters a museum, according to Icom, these procedures should apply to this work of art in order to enable its comprehension and preservation. These actions provide professionals with material to re-exhibit the artwork as accurately and respectfully as possible in the future.

This article focuses on performance art. Although this is a kind of timebased art, the preservation issues within this category may vary. Consider, for instance, kinetic art, which comes with mechanical parts that from a preservation angle offer challenges different from those tied to film reels and videotapes. A basic physical component of performance art is usually the body of the artist, which is impossible to acquire or preserve in the common meanings of these verbs. As a result, the essence of the performance artwork conflicts with the standard framework employed in museums for dealing with museological items.

The development of performance art in the 1960s related to an increasing interest in conceptual art, in which the concept became more important than the physical art object, often resulting in the use of ephemeral materials. When these kinds of artworks started to gain space in museums, some institutions reconsidered the applicability of conservation and documentation procedures, the adaptation of which often resulted in incorporating additional information regarding the artworks. In the case of performance art, this problem presented itself even more strongly because ephemerality and intangibility are elements central to this art. Documentation efforts usually play a leading role in archiving (traces of) performance art. Frequently, these efforts need to be expanded in order to compensate for the lack of materiality of performances. Moreover, decisions have to be made about which specific elements are relevant for the understanding and survival of such artworks.

If the essence of performances relates to their ephemerality, museum professionals face a dilemma when addressing this issue. By discussing various forms of registration and documentation of performance art, our argument in this article aims to provide more insights into the specific ways in which these practices aim at preserving the performativity of performance art while respecting its ephemeral nature.

The nature of performance art's ephemerality will first be addressed briefly through Lucy Lippard's seminal essay on the dematerialization of art. This is followed by our discussion of the collection of performance art in the light of Peggy Phelan's critical stance. Next, we juxtapose a case study of preserving physical remains of performances with Rebecca Schneider's framework about this matter, while Stephen Gray's argument about conservation and performance art will help us to understand the challenges involved in applying documentation practices.

In the second part of our essay, we discuss various specific forms of documenting performance art based on several case studies. These case studies all deal with bodily suffering by a female performer. The dilemma of recording performance art by means of lens-based media will be addressed in reference to Berna Reale's photo-performances, as well as Philip Auslander's essay The Performativity of Performance Documentation. Next, Marina Abramovićs perfor- 
mance in 2010 at the MoMA serves as a basis for reflection on re-enactments as preservation strategy and recordings as annotations. Furthermore, we use a performance by Yoko Ono to develop some thoughts on documentation of performances in written formats and the particular role of scripts, as also elaborated by Kevin Concannon's writing on these issues. As these case studies underscore, documentation procedures have specific implications for how performance art will survive and be passed on. In this context, studies by art theorists such as Amelia Jones will be used to identify characteristics of performativity.

Although it is possible to find modes of re-accessing these performances in the future, we also argue that performance art is too diverse for a limited set of alternative preservation strategies, in part because some artists principally frustrate any attempt at documenting their work. In this way, they emphasize the intrinsic conflict between art preservation or documentation and the essence of performance art.

\section{Dematerializing Art}

In the early 1960s, some artists started to investigate forms of expressing their artistic intentions in ways that would not be strictly associated with material objects. In the wake of the dissemination of these types of artworks in the art world, scholars began to explore the reasons contributing to the emergence of these non-material-based artworks. One of the seminal essays is The Dematerialization of Art, written in 1967 by art historian Lucy Lippard (in collaboration with John Chandler).According to art critic Philip Barcio, the essay had a great impact because the authors:

presented evidence that art might be entering a phase of pure intellectualism, the result of which could be the complete disappearance of the traditional art object. The piece grew out of, and helped contextualize, the preceding decade or so of wildly inventive conceptual art, which often left behind only ephemeral, non-archival relics, or no relics at all other than perhaps recordings of experiences (BARCIO, 2017).

Lippard argues that the new industrial form of production intensified the fabrication of art objects in a standardized structure. This system of artworks' creation demonstrated that "a number of artists are losing interest in the physical evolution of the work of art" (LIPPARD; CHANDLER, 1968: I). This shift also resulted in a trend toward the dematerialization of art, which aimed to reject art production through object-based means. While creating highly conceptual pieces, some artists intended to challenge modernist art critics by not providing them any physical information to look at. By diminishing the amount of visual material in their works, they forced critics to focus on intangible elements.

According to Lippard, non-material artworks require the viewer to take time to experience such works. They invite the viewer slowly to become involved in the idea proposed: "This time element is, of course, psychological, but it allows the artist an alternative to or extension of the serial method" (LIPPARD; CHANDLER, 1968: I). Eventually, Lippard's belief that artists' opposition to the use of materiality in creating art would challenge its commercialization was proved to be incorrect. In this respect, Barcio points out that: 
one of the early, and obvious, criticism of The Dematerialization of Art was that even though these ephemeral, conceptual concepts were less object-based, they still nonetheless result in physical phenomena. Even a performance artist creates a thing - a performancewhich can be sold as an experience or recorded (BARCIO, 20I7).

In other words, according to Barcio, this type of artwork failed its purpose of not being commercialized. At the same time, however, artists continued to produce dematerialized artworks as a way to gain attention within the field of contemporary art, mainly through works of performance art or conceptual art. The artists who explored the idea of the dematerialization of art had opened an approach, which some artists choose to adopt to this day when creating art.

\section{Debate on collecting performance art}

Recently, the Tate Modern Museum in London decided to study the process of acquisition of performances from a museological perspective, in order to deal with dilemmas involved in this kind of art for their institution. This resulted in the article Developing a strategy for the conservation of performance-based artworks at Tate. According to its authors Louise Lawson, Acatia Finbow, and Hélia Marçal, the Tate has at least 25 performance-based artworks in its collection, which underscores the need to re-elaborate the strategies to archive them. As the authors argue, however, "the ways these strategies for preservation are to be applied are still nuanced at best, as actions cannot be stored, migrated or emulated." (LAWSON; FINBOW; MARÇAL, 20 I9: I I6). They emphasize that, in dealing with performance art, using documentation procedures to preserve its traces is unavoidable because the physical form of performances is not tangible - and therefore, not conservable.

Fifteen years earlier, in 2004, art historian Peggy Phelan responded to these kinds of complexities through criticizing efforts of acquisition and documenting performance art: "While I do not believe it is possible to think of performance art as somehow beyond or outside the art market, I do continue to believe that one of the most politically radical aspects of live art is its resistance to the commodity form" (PHELAN, 2004: 57I). In her 1993 seminal book Unmarked:The Politics of Performance, Phelan (2003: 147) even argued in favor of accepting the fact that performances cannot be preserved:

Performance's only life is in the present. Performance cannot be saved, recorded, documented, or otherwise participate in the circulation of representations: once it does so, it becomes something other than performance. To the degree that performance attempts to enter the economy of reproduction it betrays and lessens the promise of its own ontology. Performance's being, like the ontology of subjectivity proposed here, becomes itself through disappearance.

Performance artist Marina Abramović confirmed Phelan's view by emphasizing the presence and particular role of the public:"Performance is a mental and physical construction that the performer makes in a specific time in a space in front of an audience, and then energy dialogue happens. The audience and the performer make the piece together" (ABRAMOVIC, 20I5). According to Abramović, there are two indispensable parts for a performance: the audience and the artist. Their encounter occurs in a predetermined time and place, which are two conditional elements for the performance's existence. Perfor- 
mances imply a moment in time for their beginning and their ending; after that, the experience involved does not exist any longer (ABRAMOVIĆ, 20I5).

However, the ephemerality of performances should not be mistaken with the impossibility of re-enactments. Abramović herself in fact hired performers to re-enact her performances during her 2010 solo exhibition in the MoMA called The Artist is Present. This is one way in which this type of performance art can be commodified, and, thus, musealized. In these cases, the creator of the performance owns not so much the performance, but the concept of the artwork, and he or she continues to have access to this concept in the future. The possible terms of such ownership or its acquisition are intriguing: what are the conditions for the frequency of re-enactments? What are the terms for the availability of artists to re-enact their own performance? Can the owner set a maximum to the number of re-enactments? Do proprietors buy a performance per re-enactment or do they purchase the concept of the artwork as a whole? Can the artist sell the same performance several times to different owners, such as in the case of engravings or photographs? If the artist passes away or is unable to be the performer, what are the conditions for re-enactment by other artists? ${ }^{3}$

Considering these various implications and complications, it is surprising perhaps that there are no official guidelines imposed or suggested by ICOM on how museums and art institutions should approach performance art. Some scholars have been researching strategies that would satisfy their needs while documenting and preserving (traces of) performance art. The International Network for Conservation of Contemporary Art (INCCA) has an online database where members have access to articles and dissertations with possible strategies to preserve contemporary art in museums. However, professionals are free to choose whatever suits their goals and expectations.

\section{Physical remains of performances in museums}

The Museum of Art of Rio (MAR) is a Brazilian institution that has been collecting contemporary art since it opened its doors in 2013. The museum has been the stage for some performances during its first years and based on instructions of the then curator and director of the museum, Paulo Herkenhoff, the remains of these performances were incorporated in the museum's collection (SILVA, 2018: 2). After these items were subjected to conservational and documentarian processes, they were incorporated as museological items under the category of Remains of Performances. For conserving and documenting these items, the museum staff applied the standardized procedures used for any museological item added to the collection ${ }^{4}$.

The practice of collecting items resulting from a performance is controversial. On a visit of MAR, as recalled by the researcher Anna Paula da Silva, museologist Bianca Mandarino showed her one of the remains of the performance Descarrego (Image I). Mandarino rhetorically questioned how such a piece would be reexhibited in the future, which is a highly relevant question from

3 Regarding such questions, the author Bianca Tinoco interviewed the Brazilian art collector Sérgio Carvalho, which resulted in the article $A$ vertigem do querer de um colecionador voraz: entrevista com Sérgio Carvalho published by the journal MODOS in 2018.

4 One of the authors consulted standard catalog records that follow the museological framework suggested by ICOM. It was not possible to assess whether or not the professionals responsible for documenting these pieces incorporated extra data in other formats to complement these records. Thus, the author did not access further data about the performances, such as interviews or videos. 
a curatorial perspective (SILVA, 20I8: I). This contemplation also involves other implicit questions: what is the purpose of collecting these remains, and what goal does it serve? What do they represent in the collection as a museological item? What would they represent when reexhibited? To what extent can these remains evoke actual experiences of the performance that took place?

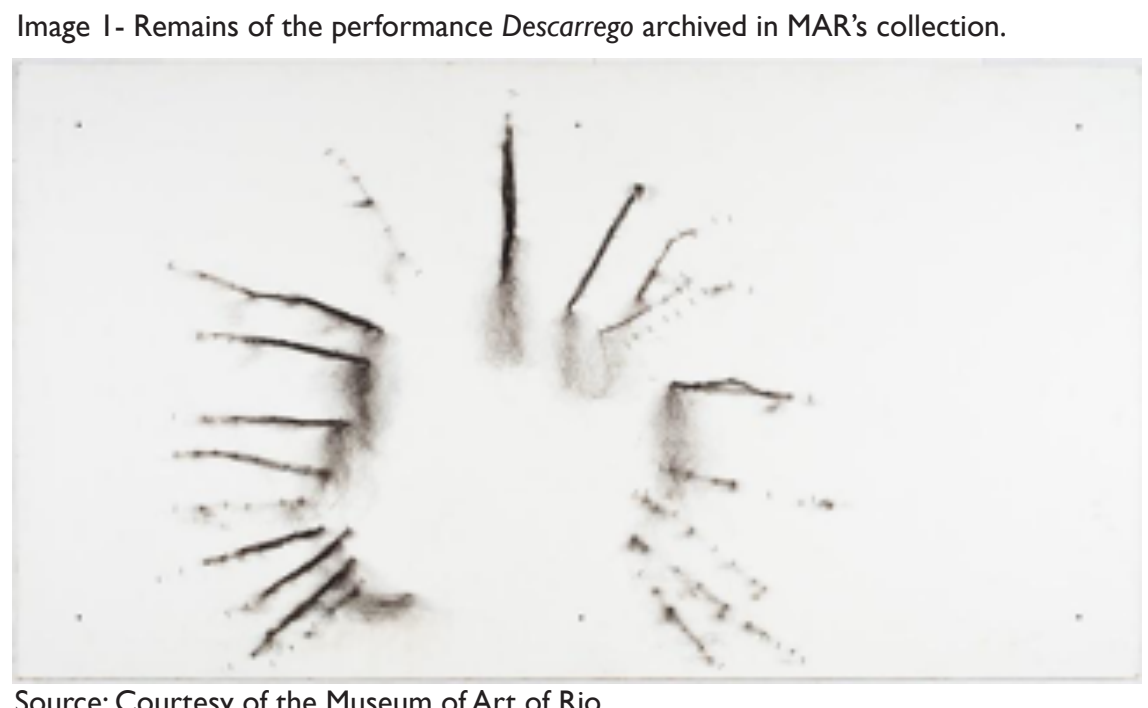

Currently, the museum has nine of these types of items, three of which are remains of the same performance. The collective EmpreZa presented this performance during a temporary exhibition. Its title Descarrego may be freely translated as "Unload" or "Discharge." During the performance, the artists stamped strands of their hair on a wooden board creating a semi-circle (Image 2). The performers forced their heads far from the board until their hair was ripped out, and the artists' heads started to bleed. The museum added three differently cataloged items of these boards with stamped hair and blood archived to its collection. It is not clear, however, if these three boards are remains of one performance involving three performers concurrently pulling off their hair or if the same performance happened three times on different occasions.

Image 2 - EmpreZa performing Descarrego in 2014 at MAR.

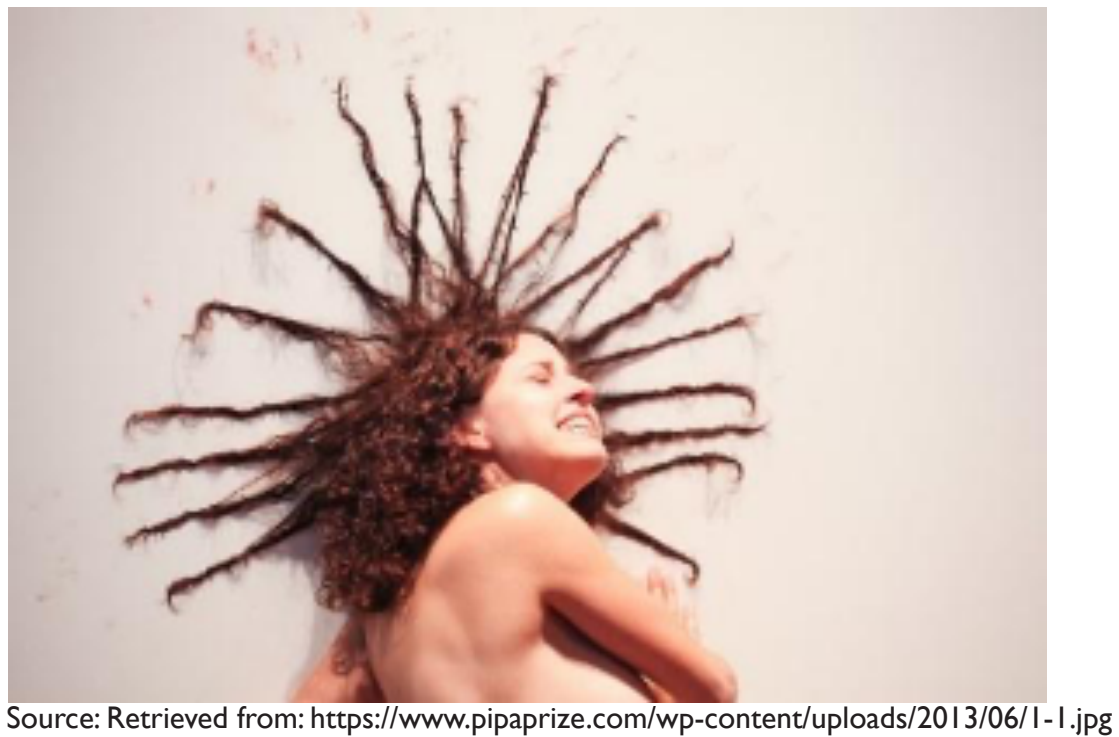


Conflicts can emerge due to the choice to incorporate these objects into the collection and to apply the equivalent procedures, as in the case of material-based artworks. The policy applicable to tangible items does not comprise aspects of performance art that transcend materiality. Information regarding the concept and intention of the artwork does not fit this format, while data about re-enactments are not included. This is why it is necessary to (re)formulate forms of preserving performance art that enable documentation of other kinds of components specific for performances as well.

According to the documentation accessed, the remains of Descarrego were donated to the museum after the performance took place. It is not clear, however, if the artists agreed with collecting these relics either as museological items or as documentation. Because there is no explicit attribution of those objects as artworks, it appears that MAR incorporated these items as remains of performances that happened in the past rather than as artworks in their own right. From the museological point of view, these items can contribute to telling the history of these performances, as a kind of documentation, but the items themselves do not replace the experience of the performance.

While the artists forced themselves away from the wooden board, they badly suffered, pushing themselves toward suffering extreme pain. This sequence of actions may have lasted minutes or hours, but in the end, the artist went home and the performance was completed. Although the intentionality of this performance was not explicitly described in the registration of the remains, ${ }^{5}$ one can presume that the essence of this artwork relates to suffering and pain, likely causing a sense of aversion in the viewers. Their disgust or repulsion while watching the performers undergoing such pain features as an element constituting the performance as much as the wooden board, the hair, and the blood. Through conserving objects with the blood spilled during the performances, these items function as traces of the sensations felt by the audience. In the case of re-enacting Descarrego, a new board has to be used each time because the processes of stamping the hair and bleeding are part of the process of the performance. As a result, the physical remains confirm the ephemerality of the original performance; they merely serve as remnants of the event. They cannot be re-used in re-enactments, but as a kind of physical fetish or relic, they may foster people's imagination and their re-interpretation of the embodied experience of the original suffering.

Regarding the preservation of material remains of performances, performance studies scholar Rebecca Schneider stresses the difficulty Western societies have in accepting performances' disappearance: "The archive is habitual to western culture. We understand ourselves relative to the remains we accumulate, the tracks we house, mark, and cite, the material traces we acknowledge" (SCHNEIDER, 200I: 100). This struggle to permit something valuable to vanish can also be perceived in the case of MAR. The curator chose to incorporate the remains of a performance because he very likely believed that these remains contained traces of the performance, even if partially, and somehow could represent the artwork (for more on the option of whether such leftovers can indeed preserve part of the performativity of a performance, see below).

The practice by MAR of archiving remains of performances could be considered a wrong decision from the perspective of Schneider's view: "Radically 'in time,' performance cannot reside in its material traces, and therefore

5 One of the authors accessed the remains' catalog record with this information virtually through MAR's database in October 2019. 
it 'disappears'” (SCHNEIDER, 200I: I00-I0I). Thus the objects in MAR's collection would not possess any trace of the performance, and archiving them is incompatible with the nature of this type of artwork. The blood that should bleed during the performance already ran cold; the physical remains disappear concurrently with the artwork itself, while conserving them is an inappropriate practice.

In comparison to conserving and collecting artistic and historical objects (or musealized objects), however, the conservation and collection of remains of performances may well serve the same purpose ${ }^{6}$. In so doing, museum professionals preserve objects that relate to the memory of a valuable event for the museum. Although the remains cannot fully represent the artwork, these objects accomplish the purpose of contributing to telling the story of that performance, such as in Abramović's above-mentioned retrospective exhibition, where objects included in her first performances were exhibited.

\section{Preserving performance art through documentation processes}

In his 2008 dissertation Conservation and Performance Art: Building the Performance Art Data Structure (PADS), Stephen Gray, a scholar in digital and cultural heritage collections, explored the problematic idea of conserving intangible artworks. According to the author, the first occurrences of performances' documentation are related to the first appearance of the artworks themselves. This likely occurred because it is the primary mode of preserving the existence of these pieces. Photographs, film - or video-recordings, and transcriptions developed into testimonies of some past events.

Although such documents do not coincide with the work, Gray argues, they are traces that represent the composition of the performance (GRAY, 2008: 8). The documentation enables an ephemeral artwork to have an afterlife, providing material to archive a memory. But it will never revive the original event. Since these afterlives of non-material contemporary artworks rely mostly on documentation practices, the standard procedures regarding documenting may well be ineffective in many cases. This led researchers to reevaluate the role of conservation, documentation, and curatorial roles for archiving these contemporary artworks. New interdisciplinary practices emerged to fit this new art genre, and according to Gray:

Documentation schemes have proved extremely effective in achie-
ving this, and so have featured heavily in this area of work, blurring
the activities of conservation and documentation. We now have se-
veral functioning data handling models intended to describe com-
plex and hybridized artworks. These schemes were primarily de-
signed to trace ephemeral, interactive, and performative elements
through the work to facilitate its future re-exhibition (GRAY, 2008:
II).

Consequently, new approaches to archive ephemeral contemporary works proved to be crucial for handling the complexity of these artworks. Regarding the performative element, Gray accentuates the idea that one should

6 The concept of musealized object is applied here according to ICOM's concept of musealisation, which affirms that "From a strictly museological point of view, musealisation is the operation of trying to extract, physically or conceptually, something from its natural or cultural environment and giving it a museal status, transforming it into a musealium or 'museum object,' that is to say, bringing it into the museal field" (DESVALLÉES; MAIRESSE, 2010: 50). 
interpret performances as something that has continuality throughout time. He considers performativity as an expression that has temporal vestiges and articulates meanings and narratives through these remains. In performance art, elements such as materials, intentions, interactions, and techniques can vary a lot, which reflects the need to be flexible while documenting performance art. If in some artworks specific aspects need to be included, in other cases different features can be indispensable. An extra complicating factor is who decides which aspects are important to document: the artist and/or the institution involved? Regardless, the vast diversity of formats in performance art underscores the need for case-based documentation (GRAY, 2008: I2).

Aware of such complexity, Gray formulated the Performance Art Data Structure (PADS), which proposes a technical format to digitally compile the metadata created while registering this type of artwork. This structure is one of the few that aim to convey such type of information. Gray proposes a structure that approaches performances from their conceptuality through focusing on creating a detailed score by interviewing the artists (and if this is not possible, other stakeholders, such as curators, technicians, etcetera) and accessing other available sources of information. The interview with the artist should be as meticulous as possible and enquire about the intentionality of the whole artwork and the versions it might have, dividing the performance into smaller subunits to examine it closely and minding tangible items used for and during the performance (GRAY, 2008: 5 I-52). However, according to Pierfrancesco Bellini and Paolo Nesi, scholars in information engineering, PADS still shows limitations while trying to embrace the diversity of performance art (BELLINI; NESI, 20 I5: 428).

The process of photographing or filming a performance might be perceived, at first sight, as a registering practice that could substitute the disappearing event. One should keep in mind, however, that the performance itself will continue to be an ephemeral experience within its own parameters and that the recording process merely translates the artwork into another medium, preserving it from what is by definition a limited perspective. By photographing and recording performances, as Gray stresses, a second structure is projected onto the performance during the process and this involves particular conflicts:

\footnotetext{
Each of these types of these documents has limitations of scope, and each medium brings the conventions associated with it as an art form in its own right, often masking these over the performance work. The well-taken photograph of an accomplished performance artwork, for instance, looks like an accomplished photograph, imposing its own conventions onto a work of different type and intent (GRAY, 2008: 7).
}

If most scholars agree that it is problematic (or even worthless) to document performance art and that the documentation will never reach a comparable status, it is interesting to mention here Amelia Jones's revolutionary view elaborated in her essay Presence' in Absentia: Experiencing Performance as Documentation. Jones argues that the original performance should not be privileged over the "specificity of knowledges that develop in relation to the documentary traces of such an event" (JONES, 1997: 12). Attending the event allows a "flesh-to-flesh engagement" but the exchanges between viewer and document of the event would be equally intersubjective. She experienced that quite a few performances became even more meaningful after some years. She even considers 
her own memories of performances she attended in the past as documents that change through time. The desire for immediacy and authenticity would be just a modernist dream (JONES, 1997: I2-I7).

\section{Photographs of performances and photo-performances}

Photographs are a standard part of museological documentation. In the case of performance art, it is not always clear how much initiative originated from the artists themselves. Some artists have appointed a (professional) photographer or video-maker to record the performance within pre-agreed formats. This process could result in two artworks, the performance itself and the product of this commissioned piece of documentation. By directing these recording practices to fit their intentions, artists become concurrently performer and (co-)producer of the photographs.

This observation leads us to the complicated issue of the difference between documentary photographs of a performance and the genre that could be called "performed photography." In The Performativity of Performance Documentation, performance and media scholar Philip Auslander notes that artists such as Cindy Sherman performed various roles in front of the camera, but her self-portraits are not called documentary photographs of a performance (AUSLANDER, 2006: 49). Auslander explains that such a "performed photograph" is an artwork, whereas a photograph as documentation is a secondary, supplementary record of a primary artwork (AUSLANDER, 2006:5I). However, what happens when we do not know whether a real performance took place? Interestingly, Auslander concludes that this hardly makes any difference because "performance art is constituted as such through the performativity of its documentation" (AUSLANDER, 2006: 55). This means that the key relationship here is not between the document and the performance, but between the document and its audience. As a result, the indexical nature of documentation would be less important than its performativity, in the meaning of having an activating character, being able to evoke a strong embodied experience of what is happening to or by the performing artist in the photograph, even when we do not know whether or how exactly the performance took place (AUSLANDER, 2006: 55).

The term performativity is used by Auslander quite similar to Amelia Jones's understanding of it. Based on seminal texts about performativity by J.L. Austin, Jacques Derrida, and Judith Butler, Jones loosely interprets the concept in her 2012 edited volume as:

\footnotetext{
the reiterative enactment across time of meaning ... through embodied gestures, language, and/or other modes of signification, opens the supposedly static work of art constructed by art history to the temporal, and to the vicissitudes of invested and embodied engagement by visitors to, participants in, or viewers of the work. ... a consideration of the performative 'de-contains' the work, reminding us that its meaning and value are contingent (JONES; HEATHFIELD, 2012: 12).
}

If Auslander relativizes the difference between documentary photography of performances and performed photography on the basis of the performative potential of both genres, our next case study combines both genres in an even more complex way. These photographs serve in the role of documenting a performance, while at the same time the performance serves as part of the production process of art photography. The term photo-performance seems to 
be appropriate for these artworks.

A triptych consisting of three photographs entitled Quando todos se calam [When everybody silences] by the Brazilian artist Berna Reale is included in MAR's collection as photos of a performance (Image 3). The characteristics of these works, however, suggest it is better to call them photo-performances. The performance underlying the triptych took place in 2009 at an open public market in a port area in the north of Brazil. This location has many scavenger animals seeking food leftovers from the market, but it is also a public space inhabited by people from the lower classes, most of whom will not be familiar with the contemporary art world. During the performance, Reale was lying naked on a table with pieces of animal viscera on top of her body. The photographs were taken while many vultures flew over Reale to grab these pieces of meat while she remained still. In an article by art scholar Susana Rocha, the artist was quoted stating that this performance relates to the "violence of silence ... [t] the silence of the 'victim/performer' is only comparable to that of the spectators, who accept their inert role in the spectacle of the attack. Only the scavengers move" (ROCHA, 20I4: 27).

Image 3 - Berna Reale, Quando todos calam (When everybody silences), 2009.

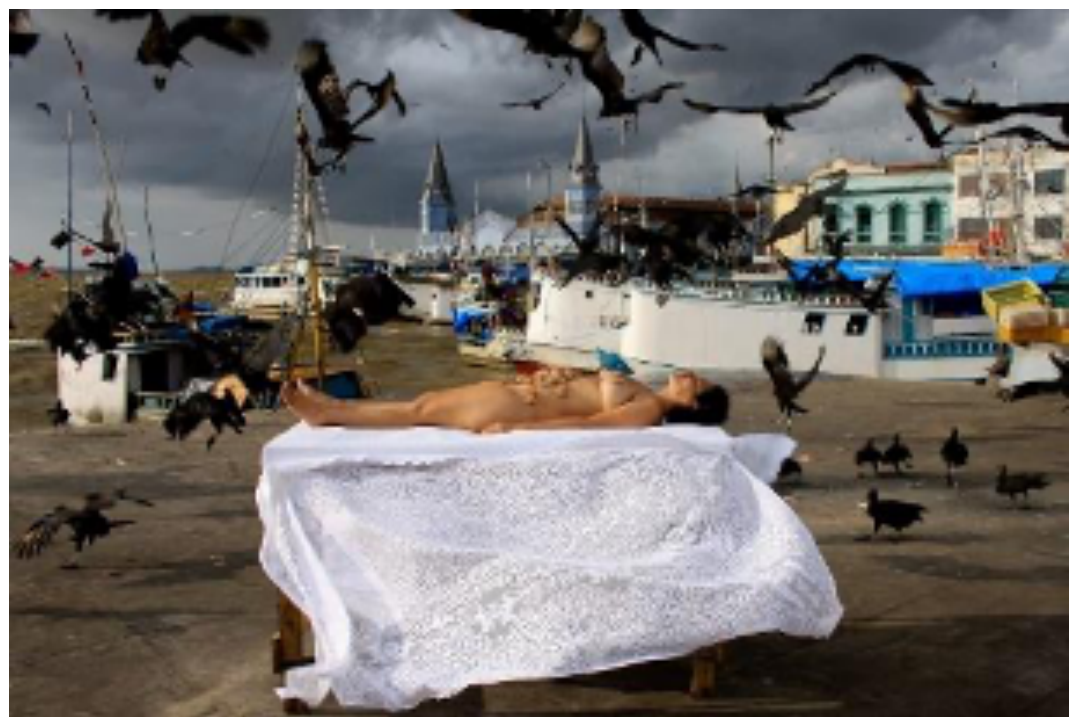

Source: Retrieved from: https://www.newcitybrazil.com/2018/09/25/forensic-artist-the-powerful-performance-art-ofcrime-scene-investigator-berna-reale/.

Reale's work often addresses themes associated with social violence and inequality. According to art and media scholar Lais Lacerda, her performances usually have a political connotation as a result of their taking place in public spaces, whereby the presence of her body incorporates multiple meanings in that specific moment and place (LACERDA; RIBEIRO, 2019: 77). The artist aims to shock those watching her perform, but by co-producing photographs and videos of her performances, she materializes this intentionality into other formats. Lacerda (2019:79) emphasizes that:

[h]er actions happen in public spaces aiming to reach the people present there at that moment and place. However, Berna's artworks outspread in videos [and photos] sent by the artist herself to galleries to be exhibited and commercialized. (...) Within Berna Reale's poetic, the videos are part of a work that can be exhibited later, the performances are not private. On the contrary, Berna does her performances in public, and the videos are a step in a process that reiterates body and video. 
The performance Quando todos se calam did not take place in a museum, and one could say that it is impossible to reenact this performance in such kind of context without compromising its poetics. This artwork relates to the in-situ aspects of performing at a market, such as the vultures and the community present there. In the case of reenacting this performance in a museum, these elements would not be present. The MAR acquired the photographs in 2013. What the museum actually added to its collection was a photo-performance that the artist produced during a performance on a specific location elsewhere in Brazil. The artist intended to perform a socio-critical act, but passers-by may have experienced the scene as a photoshoot for a disgusting commercial or a film still for a horror film. One may wonder whether the performativity of the violence in silence performance was only translated into the format of the photographic triptych, or rather strengthened. The three photographs were taken from the same angle and have the same composition, the only distinguishing element between them is the number and position of the vultures. The format of the triptych and the staged scene may evoke the association of the violence in silence in Christian iconography in altarpieces.

It is relevant to mention that MAR acquired the printed and framed version of these photographs, not the digital files. In their catalog record, these physical objects are labeled as a museological item, which supports that what was musealized here is an autonomous artwork, a photo-performance. However, as indicated above, they are formally referred to as photos of a performance as well.

The photo-performance materializes an ephemeral manifestation, which creates the paradox of materializing an ontologically ephemeral medium. Furthermore, by using performance as a process in making a photo-performance, the poetics of the artwork is finalized, and the purpose and necessity of re-performing are put into question. When re-enacting this performance, one would re-access the concept of the performance itself, but the poetics attributed to the photo-performances remain unchanged.

\section{Re-enactments: documentation and preservation through re-performing}

Marina Abramović arguably is one of the most well-recognized performers within the contemporary art world. In 2010, the Museum of Modern Art in New York City presented a retrospective exhibition of her artistic oeuvre, entitled The Artist is Present. In this comprehensive solo exhibition, items such as objects used during performances, as well as photographs, videos, and texts related to the events were displayed on one of the upper floors of the museum devoted to her past performances. In addition, curator Klaus Biesenbach and Abramović agreed to include performers re-enacting some of Abramovićs performances in the exhibition. Moreover, the artist herself re-enacted her performance Nightsea Crossings, which she presented in various locations between I98I and I986, downstairs in the museum, near its entrance section. In the original version, Abramović and her then partner Ulay sat across a table from each other while all the time staring at each other. When re-enacting this performance at MoMA, however, the audience was invited to individually make eye contact with her for as long as he or she wanted.

The photographs of Abramović's performance The Artist is Present on MoMA's website can be perceived as a case of using photographs for documen- 
ting purposes. These photographs are from a collection of installation views of the exhibition, which is a common recording process in museums for documenting exhibitions. It seems likely that the photographs available on the website were not included in MoMA's collection as independent artworks, such as in Reale's case in MAR; instead, they were perhaps archived as material that enables access to a past event that took place in the museum.

During Abramović's performance, the presence of the audience was essential and could not be excluded. This interaction was documented in several pictures from various angles showing the audience in the background watching the event; and even the facial expressions of the people sitting in front of Abramović were recorded. In one of the pictures (Image 4), we see technical equipment such as cameras, light equipment, and tapes on the floor delimiting the borders the audience can reach. In the sequence of pictures, we can observe that Abramović is not always wearing the same dress, which might indicate that there was no specific dress code scripted. In addition, in some photos there is a table placed between Abramović and the person sitting in front of her, which might also indicate an optional element in the performance. The variables of the garment and the presence of the table also demonstrate that the performance was documented more than once during the period of the exhibition.

Regarding the documentation of performances and the issue of re-performing, Abramović (2010) has claimed:

\begin{abstract}
The performance for me makes sense if it's live, and doesn't make so much sense if it's documentation. Everything else would leftover, like photograph or video, it's not the real thing.... But I really think that it's very important to re-perform the pieces even with all this danger that becomes somebody else's piece. But still you have to refer to the original source and you can make your own version. If today you can re-perform Bach, and make techno Bach out of this, why you can't re-perform the performance? It's the only way that the performance has this live element inside. It has to live like that because otherwise it's just a dead photograph on the paper or just another video.
\end{abstract}

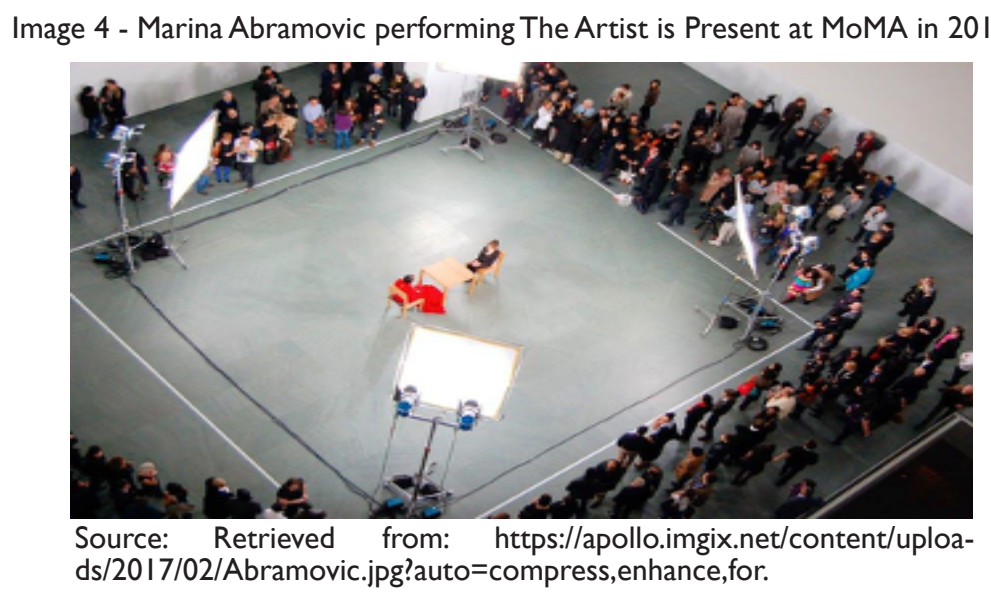

If Abramović argues against incorporating the poetics of performances in documentation formats, she surely is in favor of re-enacting performances as a kind of fragmented preservation. In her view, the essence of performances cannot be expressed through photographs and videos because performance art is a medium that can only happen in real time. Re-performing is the only way 
to re-exhibit a performance properly, even if the performer adapts the original version and incorporates his or her own identity. Interestingly, photographs are often used as a source for re-enactments, which made Auslander (2006: 48) wonder:

whether performance recreations based on documentation actually recreate the underlying performances or perform the documentation. Marina Abramović's re-enactments of other artists' performances in Seven Easy Pieces are recent examples of work that clearly plays with this slippery question.

The phenomenon of re-enactments calls forth philosopher Nelson Goodman's reflection in Languages of Art on some art forms, such as music, which have a two-stage format:"One notable difference between painting and music is that the composer's work is done when he has written the score, even though the performances are the end-products, while the painter has to finish the picture" (GOODMAN, 1976: I 14). While applying this framework to performance art, one can interpret performers as creators of the scores of performances and the re-enactments as equally valid forms of recreating the artwork, even if specific adaptations are needed or selected. Although usually the composer is not part of the score, in the case of Abramovic and most other performance artists the artist is part of the original setting.

Abramovićs opposition to documentation appears to relate to the impossibility of expressing the poetics of performance art through these processes, because applying them with recording intentions is not mentioned by her as a problem. This type of documents just works as annotations enabling art professionals to comprehend the artwork more thoroughly, which contributes to accurately re-enacting the performance.

\section{Documentation of performance art through words}

If, however, the use of visual means is perhaps intuitively the most efficient way of documenting performances, this is certainly not the only way. Yoko Ono's performance Cut Piece (Image 5) was presented for the first time in 1964, and it has been re-enacted by the artist herself several times, and more recently by other performers. During this performance, the artist kneels on the floor quietly, wearing her best pieces of clothing. A pair of scissors is placed in front of her; people in the audience are invited individually to take the scissors and cut a piece of her clothes and keep it. According to art historian Kevin Concannon, a script for Cut Piece appeared for the first time in January 1966 along with other works in a document written by Ono and entitled Strip Tease Show as the following text:

\footnotetext{
Cut Piece

First version for single performer: Performer sits on stage with a pair of scissors in front of him. It is announced that members of the audience may come on stage-one at a time-to cut a small piece of the performer's clothing to take with them. Performer remains motionless throughout the piece. Piece ends at the performer's option.

Second version for audience: It is announced that members of the audience may cut each other's clothing. The audience may cut as long as they wish (CONCANNON, 2008: 8I).
} 


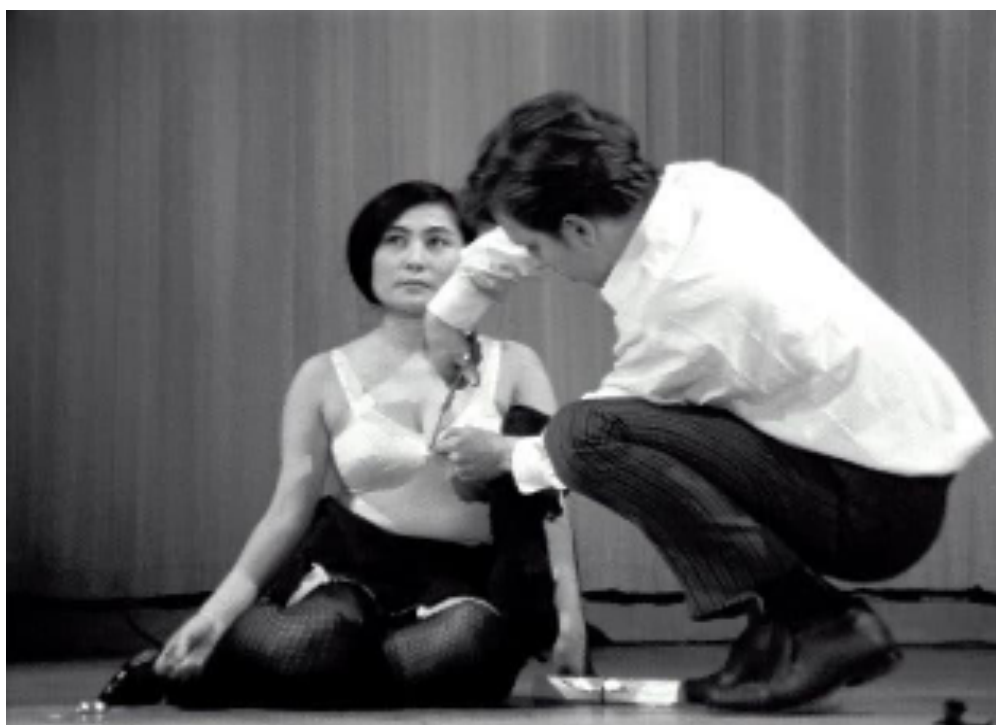

Source: Retrieved from:https://static0I.nyt.com/images/2019//0/31/books/30b ookprincenthal3/30bookprincenthal3-articleLarge.jpg?quality=75\&auto=webp \&disable $=$ upscale.

It is interesting to observe that the artist wrote two versions of the script of the performance, even though interactivity with the public is an essential element in both. This script can be perceived as a form of expressing the concept of the artwork through words. In 197I, in Ono's book Grapefruit, the artist added to the score a description stating that the performer does not necessarily need to be a woman, which was already suggested in the 1966 script by using the word "him" (CONCANNON, 2008: 82). It is interesting to note that the textual instructions hardly reflect on the visual appearance of the artist, which results in a more abstract idea. Concannon concludes that when Ono established these guidelines for the performance and referred to the performer in the third person, she dismissed the ownership of the manifestation and the first performance as the original piece. While creating a script with two different versions that could be performed by other artists, the essence of the artwork surpasses the individuality of the artist herself and allows its intentionality to be (re)interpreted by other performers.

\begin{abstract}
Having conceived Cut Piece as an event score, Ono foresaw the work's realization in a succession of presents. And from the start, she understood that in each of these presents, the work would be transformed - not from any authentic original, but from an idea into an experience- each one distinct from the others. Ono has described her instruction works-or scores-as "seeds," activated individually and collectively in the minds and actions of those who receive them. And as is often the case with her work, this germinating idea is manifest in multiple variations (CONCANNON, 2008: 82-83).
\end{abstract}

According to Concannon, then, Ono converted the intentionality of the performance into an independent idea that could be reinterpreted differently, allowing its re-enactment from its early stages. By facilitating and encouraging re-performance at such a level, the authorship of the artwork is put into question. As argued by Goodman, performing is an equally valid format of a two-sta- 
Preservando a performatividade de performances e respeitando sua efemeridade

ge artwork, but, in this case, would the performers need to pay for copyrights, such as in the music industry?

In the mid-1960s, Ono affirmed that this artwork was a "test of her commitment to life as an artist, as a challenge to the artistic ego, as a gift, and as a spiritual act" (CONCANNON, 2008: 82-83). However, art critics interpreted the piece as a striptease, a protest against violence and war (in particular the war between Vietnam and the United States), and, most recently, as a feminist work. When re-enacting the artwork in 2003, thirty-eight years after its first performance, the artist expressed that this piece was against ageism, racism, sexism, and violence. By converting the concept of the performance several times through her comments, the artist in fact encouraged different kinds of interpretations; this emancipation allowed the performativity of the performance to be revisited and reinterpreted in relation to the social and political context of a specific period.

\section{Allowing performances to be ephemeral while preserving their performativity}

While most artists will hardly object to recording practices in relation to their artistic production, this is not a consensual rule among performance artists. Some of them defend the ephemerality of performance to a degree of opposing any type of documentation in relation to their performance.A case in point is performance artist Tino Sehgal, who favors the idea of total ephemerality. Some of his performances were re-enacted several times, however, implying that the performativity of his artwork re-emerges in other bodies and on other locations through time.

Sehgal's position is in line with Phelan's view, suggesting that once a performance is done, its fate is to disappear completely. But Sehgal's concern also relates to Schneider's argument, suggesting that material traces do not possess any poetic trace and therefore should not be preserved. In contrast, Gray has argued that documentation processes can provide fruitful information about performances, and these strategies create afterlives that preserve traces of the experience lived in the moment of performance. Gray emphasizes the importance of artists' interviews to document the artist's original intention. Auslander and Jones even stress that performance art is constituted in particular through the performativity of its documentation, and the interrelated interaction with its audience. The viewpoints of the spectators can provide relevant additional material for documenting the poetics of performance and ought to be explored further from a museological perspective.

In general, performers, museum professionals, and scholars appreciate the advantages of documentation processes that allow traces of performance artworks to be archived in museums. This can be regarded as a form of accepting the artwork's disappearance while also providing modes for re-accessing it in the future. In particular through the case studies of Abramovic and Ono, it was possible to identify a recurrent view that re-enactments are one of the most appreciated forms of re-accessing performances. By applying Goodman's view regarding scores of music to an interpretation of performance art, as a concept independent of time that can have various versions and reinterpretations instead of as an original and singular occurrence that ends, a more flexible (and viable) approach arises. From this angle, performance art exceeds the material-based objects and timeframe of the original event, and therefore it 
makes more sense to consider documentation processes as strategies aimed at preserving the performance artwork's performativity, rather than as conflicting with its ephemerality.

Our argument in this essay revolved around the question of the consequences of various forms of documentation and creating afterlives for the ephemeral actions in performance art. We actually investigated how performance artworks can be allowed to remain ephemeral while preserving their performativity through documentation. As discussed, the diverse forms of documentation varied from the preservation of physical remains and the use of lens-based media or scripts to re-enactments. These different media seem to have hardly anything in common, which is not surprising because the huge variety of performance artworks and multiformity of artists' intentions ask for flexible and tailor-made solutions. Regardless of the differences we covered, our argument also provided insight into a common potential for preserving a performance artwork's performativity in various ways, while due to the impossibility of preserving the original performance artwork its ephemerality remains intact. We used the term performativity in the sense of survival and continuation of the artwork's activating character, the embodied experience evoked, and its contingent meanings. As illustrated by our case studies, their performativity can be preserved through the preservation of their flexible concepts, which start from some intention of the artist (which is an important basis, if indistinct in some cases), but only come into existence as soon as interaction with the spectator begins. They survive and continue in the process of interpretation, which starts off during the experience of a performance, and are enabled to live on due to its afterlife in documentation and re-enactments. If, then, the relationship and interaction with the audience in (some) performance artworks are highly significant, the reception history (by art critics and the general public) should be included in the documentation process as well.

As illustrated by our case studies, the embodied experience of suffering - as facilitated through traces in the afterlife of the performance - may compensate for the lost (or missed) experience of the performance artwork in the past. The forms of documenting performance art that we discussed in fact come close to this aim, each in its own way. For instance, physical remains confirm the ephemerality of the original performance because they are only a fragment and cannot be re-used in re-enactments, but may as a kind of fetish enable the imagination and re-interpretation of an embodied experience of the original suffering. Lens-based media, here represented by photography either as documentation or photo-performance, add an afterlife by means of a supplemental medium, which enables a meta-perspective on the original suffering; scripts or scores emphasize that the first stage lives on as a seed in re-enactments. Although re-enactments may offer the most alike afterlife, because a similar medium is used, they are often re-interpretations based on photo documentation and/or scripts. Through these adaptations, the ephemerality of the original work is not canceled, while the performativity is kept alive. This article demonstrated that the inability of documentation to replace the original real performance should not be considered as a problem, but as an endorsement of the ephemerality of performance art and an opportunity to continue to create flexible fragmented afterlives that preserve the performativity of performance art and prevent it from sinking into oblivion. 
Preservando a performatividade de performances e respeitando sua efemeridade

\section{References}

ABRAMOVIĆ, Marina. An art made of trust, vulnerability, and connection. Lecture in TED Talks, March 2015. Retrieved from: <https://www.ted.com/talks/ marina_abramovic_an_art_made_of_trust_vulnerability_and_connection/ transcript?language $=$ en $>$. Accessed on: $\overline{4}$ July 2020.

ABRAMOVIĆ, Marina. Documenting Performance. Artist Interview Performance. The Museum of Modern Art, 2010. Retrieved from: <https://www.khanacademy.org/partner-content/moma/artist-interview-performance/v/moma-abramovic-documenting-performance>.Accessed on: 4 July 2020.

AUGUSTO, Rachel. Creating Afterlives: Preserving Traces of Performance Art from a Museological Perspective. Thesis (Master of Arts in Arts and Culture), Leiden University, Leiden, 2020.

AUSLANDER, Philip.The Performativity of Performance Documentation. Performing Arts Journal. Cambridge, MA: MIT Press, vol. 28, n. 3, p. I-I 0, 2006.

BARCIO, Phillip.What Was the Dematerialization of Art Object? IdeelArt Magazine. London, 2 jun 2017. Retrieved from: <https://www.ideelart.com/magazine/ dematerialization-of-art>. Accessed on: 4 July 2020.

BELLINI, Pierfrancesco; NESI, Paolo. Modeling performing arts metadata and relationships in content service for institutions. Multimedia Systems. [S.I.]: Springer, vol. 2I, n. 5, p. 427-449, 20 I 5. Retrieved from: <https://link.springer.com/content/ pdf/I0.1007/s00530-0 I4-0366-0.pdf>. Accessed on: 4 July 2020.

CONCANNON, Kevin. Yoko Ono's Cut Piece: From Text to Performance and Back Again. PAJ: A Journal of Performance and Art. Cambridge, MA: MIT Press, vol. 30, n. 3, p. 38I-393, 2008.

DESVALLÉES, André; MAIRESSE, François. Key Concepts of Museology - International Council of Museum. Paris:Armand Colin, 2010.

FINBOW, Acatia. "This is propaganda 2002/2006". Performance at Tate: Into the Space of Art. London: Tate Museum, 2016. Retrieved from: <https://www.tate. org.uk/research/publications/performance-at-tate/perspectives/tino-sehgal>. Accessed on: 4 July 2020.

GOODMAN, Nelson. Languages of art: An approach to a theory of symbols. Cambridge: Hackett publishing, 1976.

GRAY, Stephen. Conservation and Performance Art, Building the Performance Art Data Structure (PADS). 2008. 72s. Dissertation - (Master of Arts in Preventive Conservation) Northumbria University, Newcastle, 2008.

INTERNACIONAL COUNCIL OF MUSEUMS - COMMITTEE FOR CONSERVATION (ICOM-CC). Terminology to characterize the conservation of tangible cultural heritage, ICOM-CC, [2008?]. Retrieved from: <http://www.icom-cc. 
org/242/about/terminology-for-conservation/\#.XXZEESgzY2w>.Acessed on: 4 July 2020.

INTERNACIONAL COUNCIL OF MUSEUMS - INTERNATIONAL COMMITTEE FOR DOCUMENTATION (ICOM-CIDOC).Statement of principles of museum documentation. ICOM, [20I2]. Retrieved from: <http://network.icom. museum/fileadmin/user_upload/minisites/cidoc/DocStandards/principles6_2. pdf>.Acessed on: 4 July 2020.

JONES, Amelia."Presence" in Absentia: Experiencing Performance as Documentation. Art Journal. [S.I.]:Taylor \& Francis, vol. 56, n. 4, p. I I-I8, 1997.

JONES, Amelia; HEATHFIELD, Adrian (eds.). Perform, Repeat, Record: Live Art in History. Bristol and Chicago, IL: Intellect Books, 2012.

LACERDA, Laís Miguel; RIBEIRO, Regilene A. Sarzi. Arte Midiática, Performance e Empoderamento Feminino: Berna Reale. $I^{\circ}$ Congresso lbero-americano sobre Ecologia dos Meios-Da Aldeia Global à Mobilidade, 2019.

LAWSON, Louise; FINBOW, Acatia; MARÇAL, Hélia. Developing a strategy for the conservation of performance-based artworks at Tate. Journal of the Institute of Conservation. [S.I.]:Taylor \& Francis, vol. 42, n. 2, p. I-2I, 2019.

LIPPARD, Lucy; CHANDLER, John. The dematerialization of art. Art International. Lugano:Art International, vol. 12, n. 2, p. 31-36, 1968.

PAÇO DAS ARTES. Duplo Olhar: Catalog of the exhibition. Retrieved from: <https://www.pacodasartes.org.br/eventos-e-acoes-de-formacao/lancamento_catalogo_duplo_olhar.aspx>.Accessed on: 4 July 2020.

PHELAN, Peggy. Marina Abramović: witnessing shadows. Theatre Journal. [S.I.]: Johns Hopkins University, vol. 56, n. 4, p. 569-577, 2004.

PHELAN, Peggy. Unmarked:The Politics of Performance. London and New York: Routledge, 2003 [1993].

ROCHA, Susana de Noronha Vasconcelos Teixeira. Berna Reale: A importância do choque e do silêncio na performance. Revista: Estúdio. Lisboa: Faculdade de Belas-Artes, vol. 5, n. 9, p. 22-30, 2014.

SCHNEIDER, Rebecca. Performance Remains. Performance Research. Aberystwyth:Taylor \& Francis, vol. 6, n. 2, p. 100-108, 2001.

SILVA, Anna Paula da. A Presença no Pós-Acontecimento: Registros de Performances em Museus. $I^{\circ}$ Encontro de Museologia da UnB, 2018.

TINOCO, Bianca. A vertigem do querer de um colecionador voraz: entrevista com Sérgio Carvalho. MODOS. vol. 2, n. 3, p. 262-272, 2018.

Submetido em 22 de junho de 2020 Aprovado em 14 de julho de 2020 